\title{
Poly(acrylic acid) surface grafted polypropylene films: Near surface and bulk mechanical response
}

\author{
L. A. Fasce ${ }^{1}$, V. Costamagna 2 , V. Pettarin 1 , M. Strumia 2 , P. M. Frontini ${ }^{*}$ \\ 1Universidad Nacional de Mar del Plata, Instituto de Investigaciones en Ciencia y Tecnología de Materiales, INTEMA, \\ J.B. Justo 4302 - B7608 FDQ - Mar del Plata, Argentina \\ 2Departamento de Química Orgánica, Facultad de Ciencias Químicas, Universidad Nacional de Córdoba, Argentina
}

Received 19 August 2008; accepted in revised form 20 September 2008

\begin{abstract}
Radical photo-grafting polymerization constitutes a promising technique for introducing functional groups onto surfaces of polypropylene films. According to their final use, surface grafting should be done without affecting overall mechanical properties. In this work the tensile drawing, fracture and biaxial impact response of biaxially oriented polypropylene commercial films grafted with poly(acrylic acid) (PAA) were investigated in terms of film orientation and surface modification. The variations of surface roughness, elastic modulus, hardness and resistance to permanent deformation induced by the chemical treatment were assessed by depth sensing indentation. As a consequence of chemical modification the optical, transport and wettability properties of the films were successfully varied. The introduced chains generated a PAA-grafted layer, which is stiffer and harder than the neat polypropylene surface. Regardless of the surface changes, it was proven that this kind of grafting procedure does not detriment bulk mechanical properties of the PP film.
\end{abstract}

Keywords: mechanical properties, depth sensing indentation, surface photo-grafting, polypropylene, films

\section{Introduction}

Owing to its useful properties, easy workability and low manufacturing costs, polypropylene (PP) is widely used for the preparation of films, fibers, plates, injection-molded as well as blow molded parts [1]. Often, insufficient surface properties preclude its use in an application to which bulk mechanical properties may be well-suited. For example dyeability, printability, paintability, adhesion, biocompatibility, antifogging, and gas permeability of PP parts can be improved by surface modification [2-9].

Efforts have been made to develop polymer modifications processes which allow the surface properties to be tailored to meet a specific requirement while retaining beneficial mechanical properties. Surface modification can be accomplished by increasing the polarity introducing special chemical functionalities like carboxylic groups, or by coating the surfaces with polar thin films, for example, poly(acrylic acid) (PAA). Surface grafting techniques including photo-initiated grafting [10-14], living radical grafting [15], ceric ion induced grafting [16], layer-by-layer ionic grafting [17] and plasma polymerization $[18,19]$ have proven to be effective to graft poly-functional monomers or polymers onto PP surfaces.

Among the methods to modify polymers, radical photo-grafting polymerisation appears as an attractive method to impart a variety of functional groups to a polymer $[20,21]$. The advantages of photografting over other available methods are: i) easy and controllable introduction of chains, ii) high density and exact localization of chains onto the

*Corresponding author, e-mail: pmfronti@fi.mdp.edu.ar

(c) BME-PT and GTE 
surface, iii) covalent attachment of chains which avoids delamination and assures long-term chemical stability of introduced chains, in contrast to physically attached layers [1].

Low energy radiation, such as UV light, is frequently used to initiate surface modification. The ability of graft co-polymerization to quickly change the surface properties in a tunable fashion allows for the development of a product that can be adapted on-demand to a particular application.

Modification of PP films through grafting at relatively low amounts were previously demonstrated to be an effective approach to functionalize PP providing a defined, stable, organic foundation for subsequent surface modification of various types [22]. Costamagna et al. were able to modify exclusively the surface of bi-oriented PP films by grafting reaction of poly(acrylic acid) (PAA) [23]. They showed that values of the permeability coefficient of oxygen, nitrogen, carbon dioxide, carbon monoxide, argon, methane, ethane, ethylene, and propane across the grafted films undergo a marked drop. Their morphology investigations by Atomic Force Microscopy (AFM) suggested the initial formation of PAA brushes attached to the PP surface at short time of reaction followed by the generation of a network by cross reaction between grafted growing chains, brushes entanglements and strong hydrogen bonds [24]. The improvement in barrier properties was attributed to the formation of such a rigid PAA layer onto the PP surface [24].

Despite it has been claimed that surface grafting theoretically occurs without detriment of the bulk mechanical properties of the polymer [25], undesirable changes in the mechanical performance of different polymeric films modified by photo-grafting techniques have been reported (see for example in $[22,26-28])$. To a large extent, the tendency and level of concomitant changes in the material properties depend on whether crosslinking or degradation dominates during the irradiation of the polymer $[29,30]$. UV irradiation may induce the formation of free radicals, which promotes crosslinking. This in turn minimizes the anisotropic character of the polymer leading to an increased degree of molecular disorder. If this occurs, bulk mechanical properties of a polymeric film would be impaired since they are highly dependent on molecular orientation.
The present paper is focused on determining the mechanical properties of a bi-oriented PP film before and after surface photo-grafting with PAA chains. To this aim the bulk mechanical behavior was characterized by evaluating uniaxial tensile deformation, quasi-static fracture and dart impact properties. In addition depth sensing indentation experiments [31-36] were carried out in order to gain a deeper insight into differences in surface mechanical characteristics of PAA-grafted and neat films.

\section{Experimental section}

\subsection{Film grafting procedure}

A commercial polypropylene film (PP) (Converflex S.A., Buenos Aires, Argentina), was surface modified by radical grafting polymerisation initiated by UV light. The appropriate reaction conditions were previously investigated [23]. The procedure was as follows: Acrylic acid was used as grafting co-monomer. The initiator benzophenone (Fluka AG, Buchs, Switzerland) was dissolved in the acrylic acid (BASF, New Jersey, USA) and distilled water was added. The solution in contact with the PP film was enclosed into a photo-reactor and irradiated with UV light (medium pressure UV lamp Engenlhard-Hanovia, Slough, England) under nitrogen atmosphere at room temperature for $10 \mathrm{~min}$. The grafted film was extensively washed with a $\mathrm{NaOH}$ solution $(\mathrm{pH}=8)$ in order to remove traces of un-reacted monomer and formed homopolymer as well as to extract rests of the initiator.

Before characterization, surface modified films were left in a pH 8 solution for $24 \mathrm{~h}$ in order to disrupt the hydrogen bonds.

The thickness $(t)$ of the neat PP film determined with a micrometer was $34 \pm 1 \mu \mathrm{m}$. The difference between the thickness values of the neat and the PA-grafted films was determined with a Mitutoyo coordinate measuring machine. Measurements made on at least ten different locations for each sample yielded an averaged value of $4.5 \mu \mathrm{m}$ for the PAA layer.

Hereafter, unmodified films and surface modified films are designated as PP and smPP films, respectively. 


\subsection{Physical and chemical characterization}

\subsubsection{Chemical structure}

Fourier transform infrared spectroscopy (FTIR) measurements of the surface modified films were obtained from a Nicolet 5 SXC FTIR spectrophotometer operating in the transmission mode in order to characterize the chemical modification. Each spectrum was collected by cumulating 32 scans at a resolution of $8 \mathrm{~cm}^{-1}$.

Gravimetric measurements of films before and after grafting reactions were carried out to determine the grafting percentage by means of the Equation (1) [37, 38]:

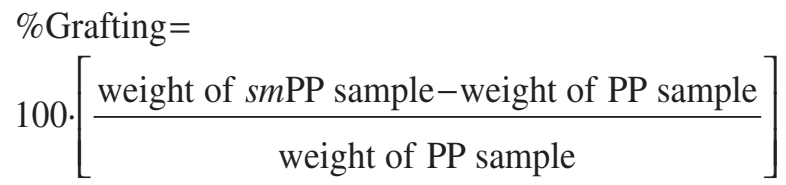

The weight of grafted layer was also estimated by volumetric titration of the $\mathrm{COOH}$ groups grafted onto the PP surface with a $0.01 \mathrm{M} \mathrm{NaOH}$ solution.

\subsubsection{Surface feature, topography and roughness}

Scanning electron microscopy (SEM) observations were made by using a Jeol JSM-6460LV scanning electron microscope operating at an accelerated voltage of $15 \mathrm{kV}$. Sample surfaces were coated with a thin layer of gold.

Scanning probe microscopy (SPM) analyses were made using the SPM module of the Triboindenter Hysitron. Sample surfaces were explored with an imaging type tip at a scan rate of $0.5 \mathrm{~Hz}$ and a setpoint force of $1 \mu \mathrm{N}$. The arithmetic mean surface roughness $\left(R_{a}\right)$ was calculated from the SPM images as the average of the absolute values of the surface height deviations measured from the mean plane within a box of $400 \mu \mathrm{m}^{2}$.

\subsubsection{Wettability}

Static contact angle measurements were performed by the sessile drop method at room temperature. The 'NIH' image software was used with a MV-50 camera and a magnification of $6 \times$. The contact angles of water droplets on PP and surface modified PP surfaces were used to determine the change in hydrophilicity of the film surface. Five measurements were recorded and an average contact angle was calculated for each material [39].

\subsubsection{Transparency}

Light transmittance measurements were carried out by using a Leica DMLB microscope incorporating a photo-detector in its optical path. The light transmittance signal $\left(I_{T}\right)$ measured for PP and smPP samples were used to estimate the loss of film transparency according to the following definition (Equation (2)):

$$
\text { Loss of transparency }=\frac{I_{T}(s m \mathrm{PP})-I_{T}(\mathrm{PP})}{I_{T}(\mathrm{PP})} \cdot 100
$$

\subsubsection{Microstructure and orientation}

The main factors that determine the mechanical properties are the molecular orientation and the crystalline level.

The anisotropy developed during the planar deformation that films underwent during blowing was not identifiable from the simple naked eye inspection. The main film orientation directions were identified from the birefringence using polarizing microscopy. Machine (MD) and transverse (TD) directions of biaxially oriented films coincide with the two orthogonal axes defined by the four positions in which light extinguishes when the film is rotated under cross polarizers [40].

The crystalline fraction $\left(X_{c}\right)$ was determine using thermal analysis. DSC measurements were performed in a Perkin Elmer Pyris 1 equipment at $10^{\circ} \mathrm{C} / \mathrm{min}$. For the sake of simplicity, samples were directly put in the DSC capsules. In $X_{c}$ calculations, the enthalpy of fusion of $100 \%$ crystalline PP was taken as $209 \mathrm{~J} / \mathrm{g}$ [41].

\subsection{Near Surface mechanical properties}

Near surface mechanical properties of the films were investigated up to the micron scale using a Hysitron Triboindenter ${ }^{\circledR}$ testing system [http:// www.hysitron.com]. While a diamond indenter drives into the film surface, the system is able to collect the applied force and displacement data. Samples were indented with a conospherical dia- 
mond tip of nominal radius of curvature equal to $1 \mu \mathrm{m}$. Indentations were performed using trapezoidal loading curves in order to minimize the 'nose effect' caused by the viscoelastic nature of polymers [33]. Maximum applied loads were varied between 4000 and $9000 \mu \mathrm{N}$ at a constant loading rate of $250 \mu \mathrm{N} / \mathrm{s}$. The holding time between loading and unloading stages was $20 \mathrm{~s}$. Indentations were load-controlled and repeated at least 20 times for every load on different locations of the films surfaces.

The Oliver-Pharr method [42], which proposes the estimation of the slope of the unloading curve by first fitting the entire unloading data, was employed to determine reduced elastic modulus $\left(E_{r}\right)$ and the hardness $(H)$ of the materials. The reduced elastic modulus is related to the elastic modulus of the sample $(E)$ and the contact stiffness $(S)$ by Equations (3) and (4):

$$
\begin{aligned}
& E_{r}=\left[\frac{1-v^{2}}{E}+\frac{1-v_{i}^{2}}{E_{i}}\right]^{-1} \\
& E_{r}=\frac{1}{2}\left(\frac{\pi}{A_{\max }}\right)^{\frac{1}{2}} S
\end{aligned}
$$

where $v$ is the Poisson's ratio and subscript $i$ denotes the indenter material. $A_{\max }$ is the surface contact area at the maximum displacement. The contact stiffness $(S)$ is the slope of the unloading curve taken as the first derivative in the maximum depth of a fitted power law function of the unloading segment of the curve.

The material hardness $(H)$ is defined as the maximum load, $P_{\max }$, divided by the projected area of the indentation under this load, see Equation (5):

$$
H=\frac{P_{\max }}{A_{\max }}
$$

The surface contact area versus contact depth function of the tip $A\left(h_{c}\right)$ was empirically determined by performing multiple indentations on a polycarbonate block of known $E_{r}$ as suggested in [33]. The obtained calibrated area function was used in the computation of $E_{r}$ and $H$ values (Equations (3) and (4)).

\subsection{Bulk mechanical properties}

Both PP and surface modified PP films were tested along with (MD) and transversely to the machine direction (TD) at room temperature. Experiments were carried out in an Instron 4467 universal testing machine at a crosshead speed of $10 \mathrm{~mm} / \mathrm{min}$.

Uniaxial tensile tests were performed on dumbbellshaped specimens, which were die-cut from the films. Longitudinal strain was measured with the aid of a video extensometer in which the deformation of the material is assessed from the current distortion of a close array of two ink dots printed onto the samples prior to deformation [43]. Yield stress $\left(\sigma_{y}\right)$ was determined as the stress where two tangents to the initial and final parts of the load-elongation curve intersect [44]. Elastic modulus was calculated from the stress-strain curves. Properties were averaged from at least five tests.

Fracture experiments were performed using Deeply double edge-notched samples (DENT, Mode I) prepared by cutting the sheets into rectangular coupons of total length $Z_{t} 80 \mathrm{~mm}$ (with a length between the grips of $Z=60 \mathrm{~mm}$ ) and a width $W=$ $40 \mathrm{~mm}$. A special device was used to perform the two notches, allowing them to be perfectly aligned. Notches were then sharpened by pushing through the material a fresh razor blade into the tip to a depth of $1 \mathrm{~mm}$. The length of each notch $a$ was $10 \mathrm{~mm}$.

Fracture toughness was determined by using the $J$-integral approachl, as defined by Equation (6):

$$
J_{c}=\frac{\eta U_{t o t}}{B(W-a)}
$$

with $U_{t o t}$ the overall fracture energy i.e. the total area under the load-deflection curve, $B$ the thickness of tested specimens, and $\eta$ a geometry factor expressed as Equation (7) [45]:

$$
\eta=-0.06+5.99\left(\frac{a}{W}\right)-7.42\left(\frac{a}{W}\right)^{2}+3.29\left(\frac{a}{W}\right)^{3}
$$

In order to complete the bulk characterization, dart impact experiments were carried out since it has been shown that such tests are very sensitive to surface modifications in polymeric systems [46]. Dart impact experiments were conducted on a Fractovis Ceast falling weight type machine at room temperature at $3 \mathrm{~m} / \mathrm{s}$, using an instrumented high-speed 
dart with hemispherical end onto disk specimens of $80 \mathrm{~mm}$ of diameter. The modified surface was placed opposite to the impact tip in order to induce tension loads on the modified surface. The thickness related energy $(U / t)$ was determined by numerical integration of the experimental load-displacement data. Disc maximum strength $\left(\sigma_{d}\right)$ was computed from the recorded traces through the following relationship (see Equation (8)) [47]:

$\sigma_{d}=2.5 \frac{P_{\max }}{t^{2}}$

\section{Results and discussion}

\subsection{Surface modification}

FTIR spectra of the films are shown in Figure 1, in which an intense $-\mathrm{C}=\mathrm{O}$ absorption $\left(1718 \mathrm{~cm}^{-1}\right)$ characteristic of polyacrylic acid is seen in the curve of the surface modified PP film.

The grafting percentage obtained by both techniques (gravimetric measurements and volumetric titration) was $12.9 \%$ (Equation (1)).

PP and surface modified PP films displayed melting endotherms of very similar shape: besides the main melting peak at $168^{\circ} \mathrm{C}$ a small peak appeared at about $160^{\circ} \mathrm{C}$ (Figure 2). During heating, the disorientation process that occurs in crystalline oriented polymers is often accompanied by dimensional shrinkage. For isotactic polypropylene, Sun and Magill [48] demonstrated that shrinkage and melting take place concomitantly producing multiple melting peaks. Since any slight difference in $X_{c}$ values of PP and surface modified PP samples is within experimental error, PP crystalline fraction, $X_{c}$, is about $40 \%$. Based on the DSC results, it

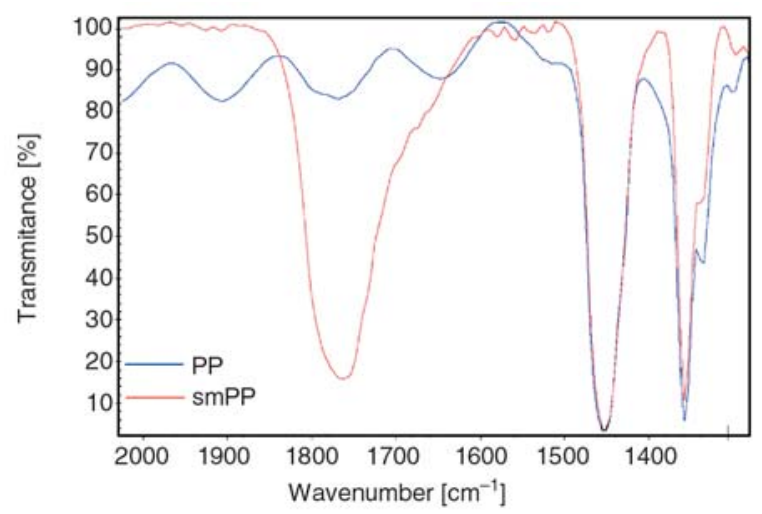

Figure 1. FTIR spectra of PP and surface modified PP films

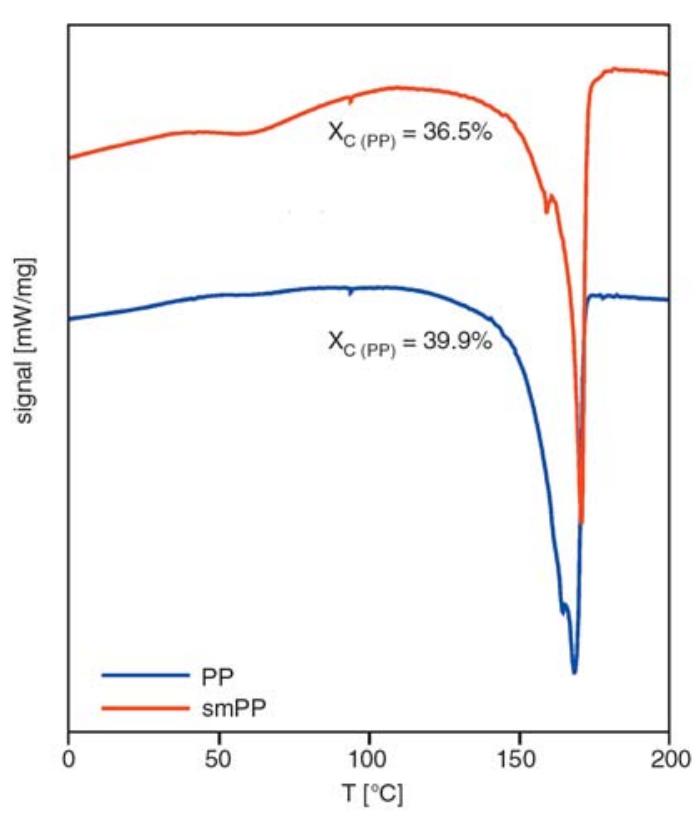

Figure 2. DSC thermograms showing the melting behavior of PP and surface modified PP films

appears that the grafting process did not affect supramolecular structure of the neat PP film.

SEM and SPM images of both films surfaces are shown in Figures 3 and 4, respectively. It is clear

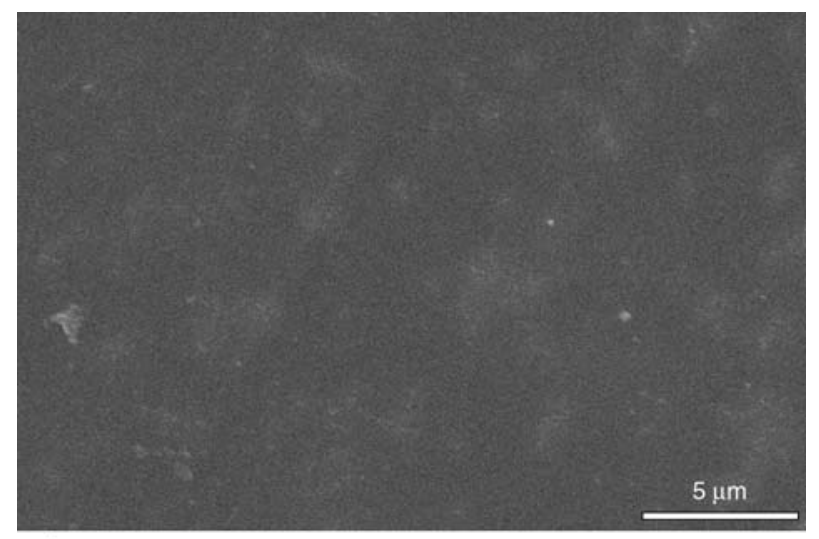

a)

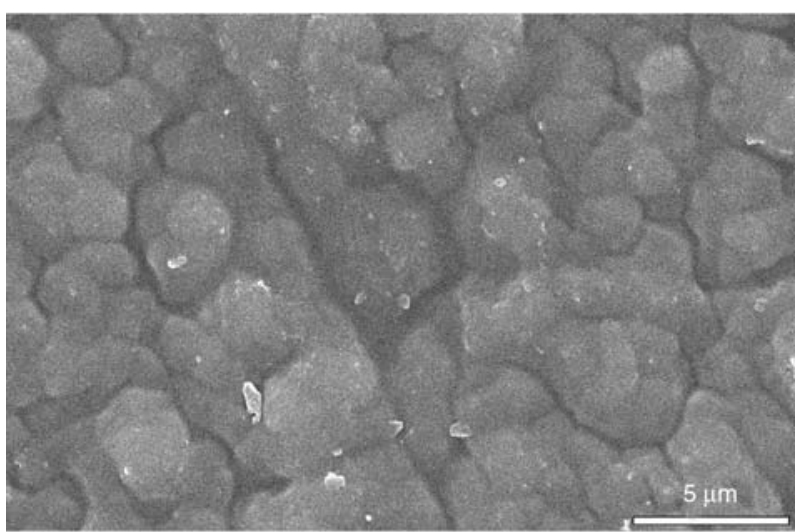

b)

Figure 3. SEM microgrpahs showing the topography of PP (a) and surface modified PP (b) films 


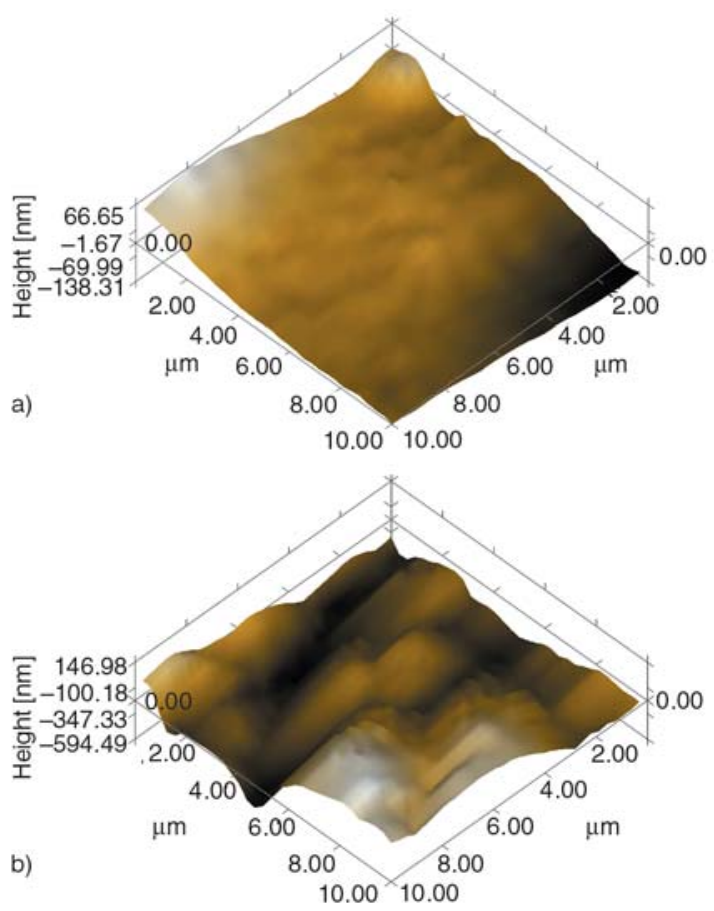

Figure 4. Typical SPM images of PP (a) and surface modified PP (b) film surfaces used in roughness measurements

that the surface topography of PP and grafted PP films is significantly different. The PP film exhibits a smooth surface pattern free of defects and a surface roughness, $R_{a}$, equal to $21 \mathrm{~nm}$. On the contrary, the surface of modified film is rougher $\left(R_{a}=\right.$ $357 \mathrm{~nm}$ ) showing a pin-hole free, textured dense pattern, composed of a number of clusters distributed along the substrate in a 'patchy' fashion. The patches join together to form a continuous structure.

The transmitted light intensity measured through the surface modified PP film was 16\% lower than the one measured through the neat PP film. The additional scattering arises from the enlarged surface roughness displayed by grafted films since crystalline fraction was not altered.

Figure 5 shows images of a water droplet on the surface of PP and grafted PP films. The liquid contact angles on both films were markedly different: $79.7 \pm 1.1^{\circ}$ for the PP film surface and $18.6 \pm 3.5^{\circ}$ for the PAA grafted surface. The smaller contact angle of water droplet on the surface grafted film indicates a stronger hydrophilicity nature on the surface given for grafting modification. This increase in the hydrophilicity and wettability is due to the presence of a hydrophilic grafted chain of the PAA and it is markedly increased by the electrostatic repulsion

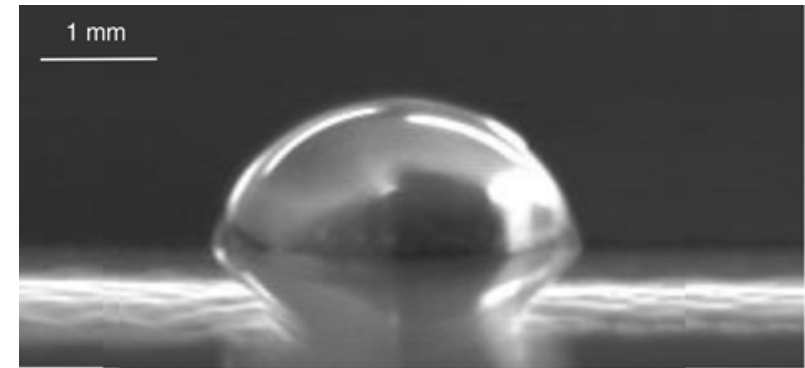

a)

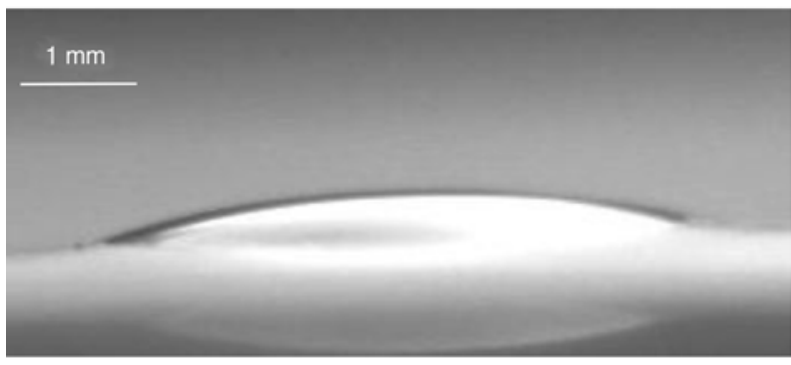

b)

Figure 5. Pictures of typical sessile droplets found in contact angle experiments for PP (a) and surface modified PP (b) films

between the negatively charged carboxylic groups $\left(-\mathrm{COO}^{-}\right)$present in the grafted chains.

\subsection{Near surface mechanical properties}

Depth sensing indentation experiments have been performed to characterize the mechanical properties of the near surface layer of the neat and grafted PP films. Typical curves are shown in Figure 6 while parameters obtained from indentation tests are shown in Figure 7 as a function of maximum applied load. The measured load-depth curves for the grafted films appeared widely scattered (Figure 6b) in contrast to the neat film traces. Reduced elastic modulus (Figure 7a) as well as hardness (Figure 7b) of PP and surface modified PP films are not dependent on penetration depth, which actually increased as the maximum load applied increased (Figure 7c).

The values of nanomechanical parameters of neat PP films are in coincidence with the ones reported in literature for other PP grades [49-51].

$E_{r}$ and $H$ values of the modified film correspond to the PAA grafted layer since the indentation depths achieved during the experiments were lower than the thickness of the grafted layer (Figures 7a to 7c). These values appeared widely scattered, but they were always larger than their homologues corresponding to neat films. The scattering arises from 

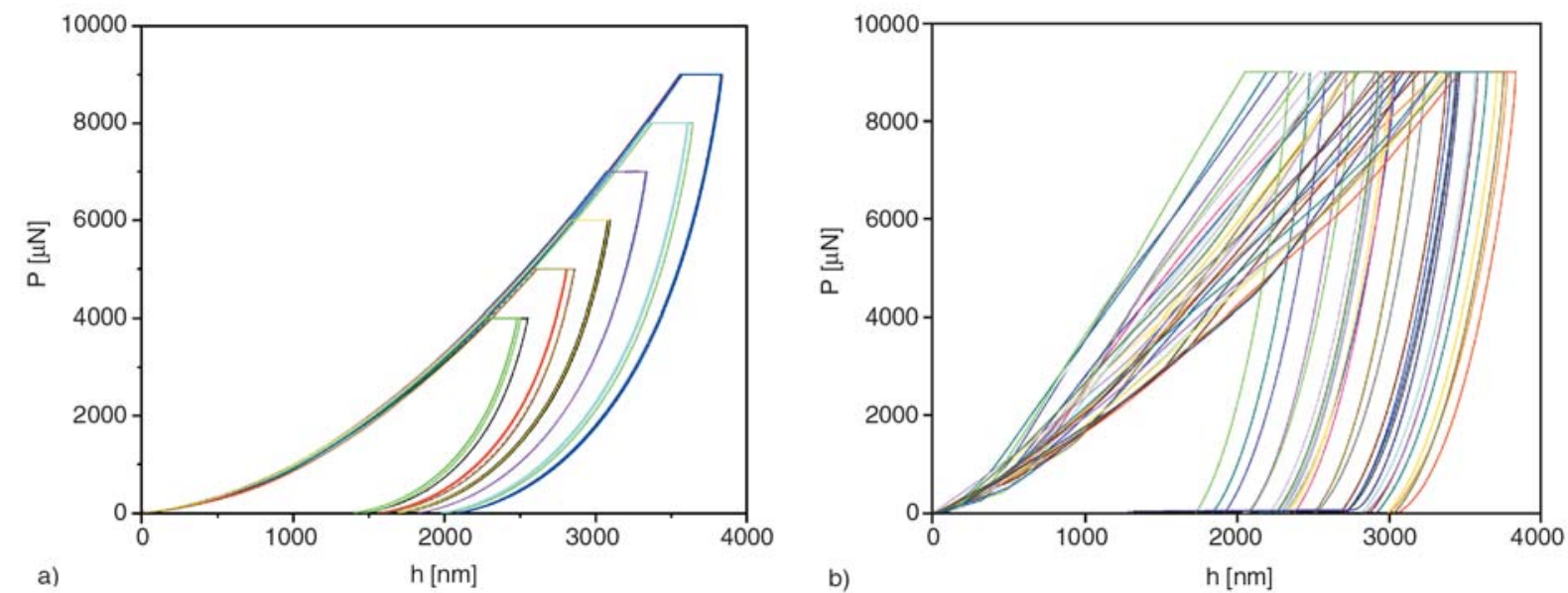

Figure 6. Typical load and depth curves obtained in indentation experiments for a) PP samples at different maximum applied loads and b) smPP samples at the same load
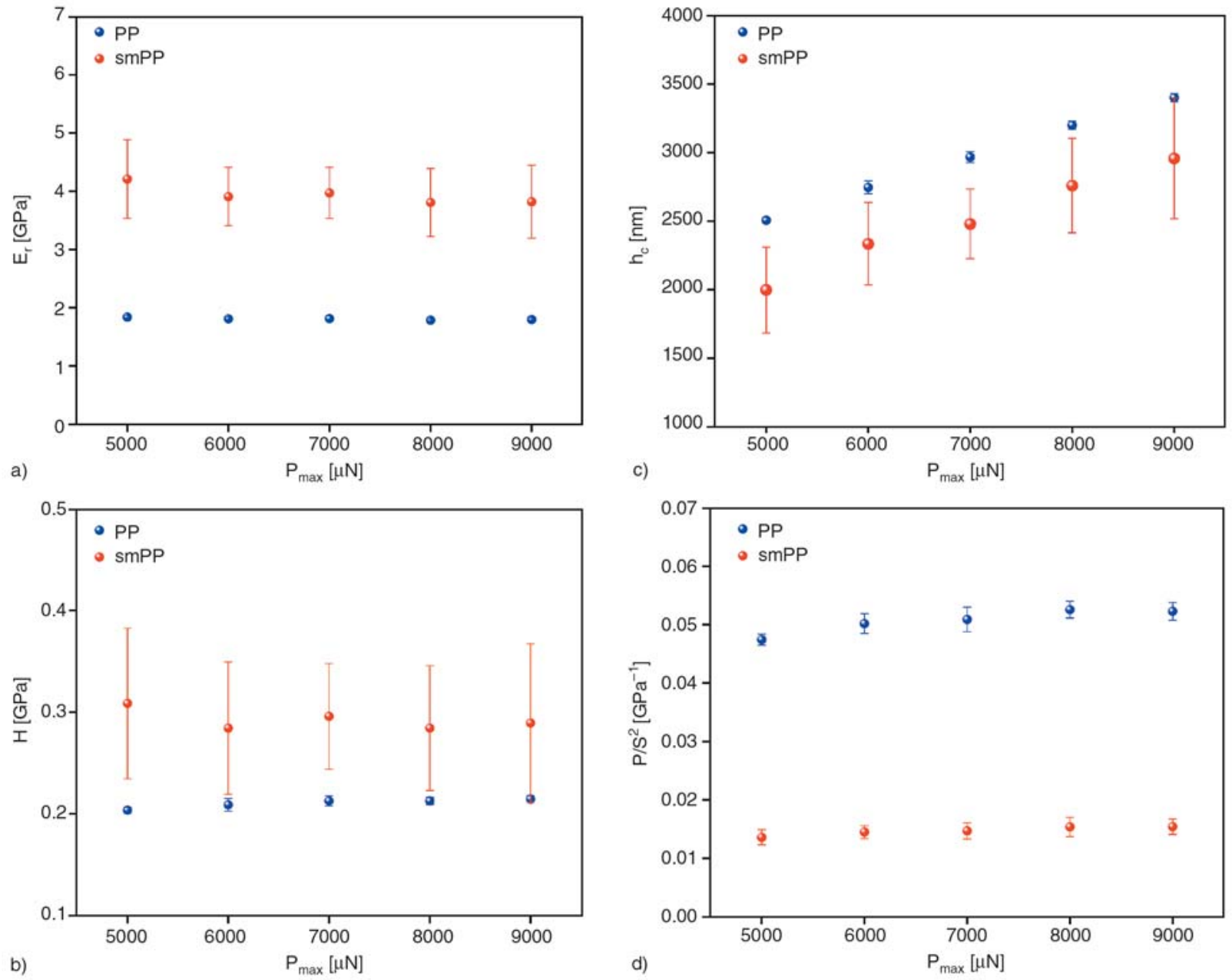

Figure 7. Reduced elastic modulus (a), universal hardness (b), contact depth (c) and $P / S^{2}$ (d) parameters arisen from nanoindentation experiments

the large surface roughness of the PAA layer, which was a consequence of the grafting process (see section 3.1.). It is well known that if the surface roughness is too large the actual penetration depth of the indenter may be smaller than the sensed depth [52]. This yields large errors in the calculated contact area values $\left(A_{\max }\right)$, which generates a wide scattering in the parameters calculated through Equations (3) and (4) from multiple indents in a material. Note that as $H$ is proportional 
to $1 / A_{m}$ and $E_{r}$ is proportional to $1 / A_{\max }^{1 / 2}$, scattering in hardness values is wider than in elastic modulus values.

Joslin and Oliver [52] proposed an alternative method to analyze nanoindentation data for samples that are less than ideal surfaces. By combining Equations (4) and (5), it emerges that, according to Equation (9):

$$
\frac{P_{\max }}{S^{2}} \propto \frac{H}{E_{r}^{2}}
$$

The ratio of the maximum load to the stiffness squared parameter, $P_{\max } / S^{2}$, is a mechanical property that describes material's resistance to plastic deformation. When the indenter is forced a certain distance beyond the initial contact point, the interference between the indenter and the specimen is accommodated in two ways: elastic deformation and plastic (or permanent) deformation. For a given hardness, the lower the modulus, the greater the elastic accommodation and the smaller the permanent damage to the specimen when the indenter is removed. On the contrary, for a given modulus, if the hardness is increased, the plastic strain is reduced. The $P_{\max } / S^{2}$ ratio is a directly measurable experimental parameter that is independent of the contact area provided the hardness and elastic modulus do not vary with depth.

Indentation data were re-analyzed following Equation (9) and plotted in Figure 7d. The scattering in the $P_{\max } / S^{2}$ parameter is now negligible, confirming that the sole source of scattering is the large surface roughness of the surface modified PP film.

$H / E_{r}^{2}$ data determined for materials displaying different mechanical characteristics are plotted together versus the $P_{\max } / S^{2}$ parameter in Figure 8. Note that the resistance to plastic deformation of the PAA layer falls close to the values displayed by amorphous glassy polymers, specially polymethylmethacrylate (PMMA). This result is consistent with the chemical similarity between PAA and PMMA and the extra stiffness usually shown by polymer brushes subjected to neighboring chains confinement [53].

From depth sensing indentation experiments it emerges that the graft amorphous PAA layer is stiffer, harder and more resistant to mechanical compression and indentation than the neat surface thanks to its glassy nature.

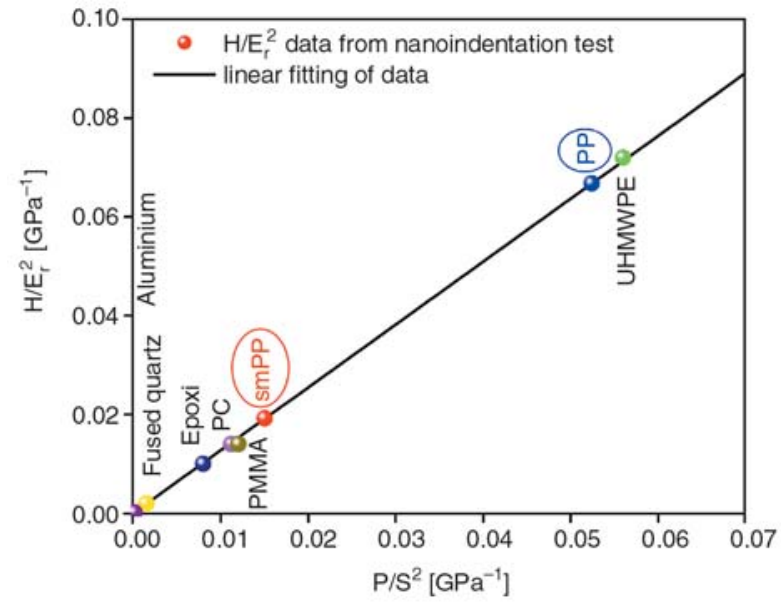

Figure 8. $H / E_{r}^{2}$ parameter for several materials tested by depth sensing indentation: $\mathrm{Al}$ (aluminum), Qz (fused Quartz), PC (polycarbonate), PMMA (polymethymethacrylate), UHMWPE (ultra high molecular weight polyethylene)

\subsection{Bulk mechanical properties and fracture behavior}

Typical uniaxial tensile stress-strain curves are shown in Figure 9 while the derived uniaxial tensile parameters are listed in Table 1. PP and surface modified PP films showed the same behavior under uniaxial tensile deformation. In each curve the stress increases continuously with strain, showing only a change of slope near the yield point. As expected, films show themselves to be highly anisotropic displaying large differences in Young's modulus and yield point between TD and MD directions. The recognition that molecular orientation produces important variations in the mechanical properties of polymers has long been established [54].

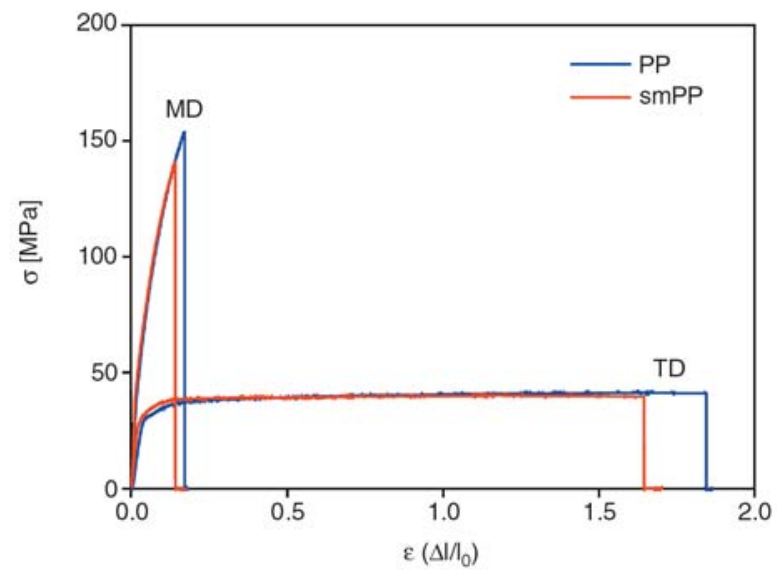

Figure 9. Typical stress-strain curves of PP and surface modified PP samples under uniaxial drawing 
Table 1. Summary of bulk mechanical properties

\begin{tabular}{|c|c|c|c|c|c|c|}
\hline \multirow{2}{*}{\multicolumn{2}{|c|}{$\begin{array}{c}\text { Test } \\
\text { Parameter }\end{array}$}} & \multicolumn{2}{|c|}{ Uniaxial tensile } & \multirow{3}{*}{$\begin{array}{c}\text { Fracture mechanics } \\
\mathbf{J} \boldsymbol{c}[\mathbf{N} / \mathbf{m m}]\end{array}$} & \multicolumn{2}{|c|}{ Dart impact } \\
\hline & & E [GPa] & $\sigma_{\mathrm{y}}[\mathrm{MPa}]$ & & $\mathrm{U} / \mathrm{t}[\mathrm{J} / \mathrm{mm}]$ & $\sigma_{d}[\mathrm{GPa}]$ \\
\hline \multirow{2}{*}{ PP } & MD & $3.6 \pm 0.8$ & $35.6 \pm 0.7$ & & \multirow{2}{*}{$32.1 \pm 6.4$} & \multirow{2}{*}{$115.6 \pm 17.9$} \\
\hline & TD & $1.1 \pm 0.2$ & $24.2 \pm 0.7$ & $20.3 \pm 1.9$ & & \\
\hline \multirow{2}{*}{$s m \mathrm{PP}$} & MD & $3.7 \pm 0.2$ & $34.3 \pm 1.7$ & $41.7 \pm 2.8$ & \multirow{2}{*}{$30.6 \pm 4.8$} & \multirow{2}{*}{$113.9 \pm 23.9$} \\
\hline & TD & $1.2 \pm 0.3$ & $22.6 \pm 2.6$ & $22.6 \pm 2.0$ & & \\
\hline
\end{tabular}

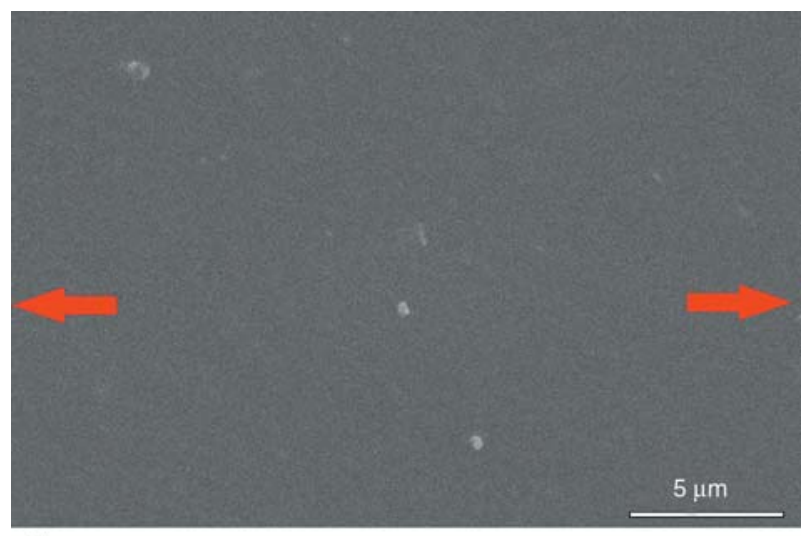

a)

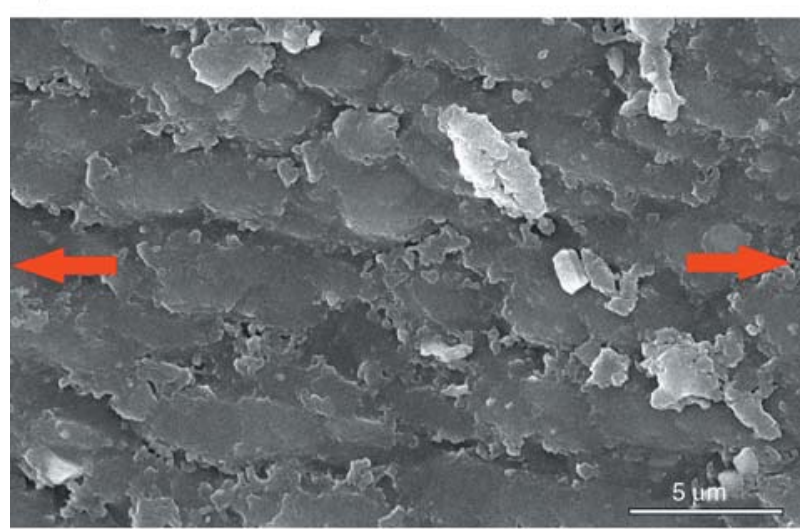

b)

Figure 10. SEM micrograph of uniaxial tensile deformed PP (a) and surface modified PP (b) samples. Red arrows indicate drawing direction.

SEM inspection of stretched surface modified PP samples (Figure 10) revealed that during deformation disruption of the clustered structure of the PAA-grafted layer occurred without transferring cracks to the substrate suggesting weak interactions between chains.

Typical load-displacement traces displayed by DENT samples are shown in Figure 11. Again, the feature of the curves depended on stretching direction but not on surface modification. All samples exhibited initially stable crack propagation followed by sudden unstable crack growth up to final fracture. The feature of the fracture surfaces in the stable propagation regime is illustrated in Figure 12. No striking differences are evidenced in

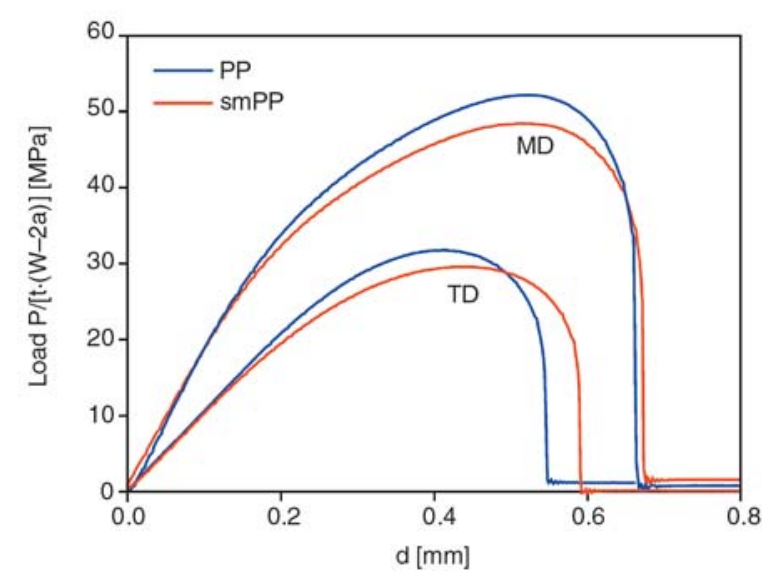

Figure 11. Typical normalized load vs. displacement curves of PP (a) and surface modified PP (b) DENT samples

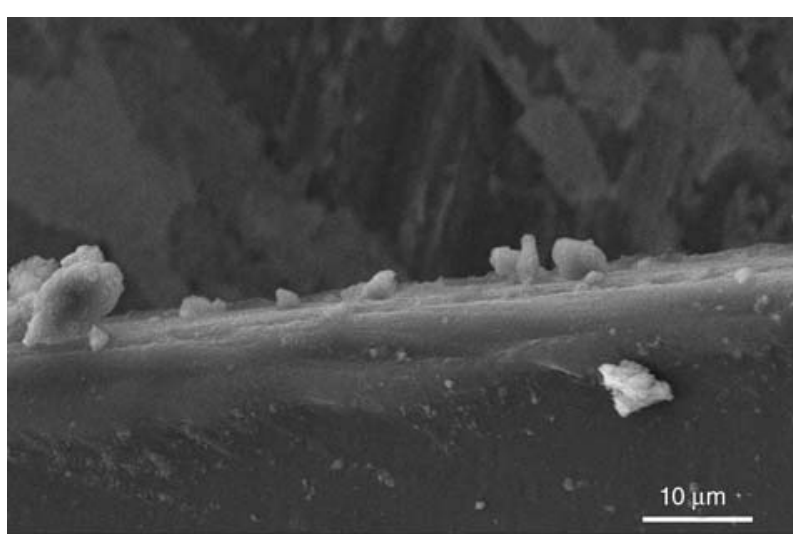

a)

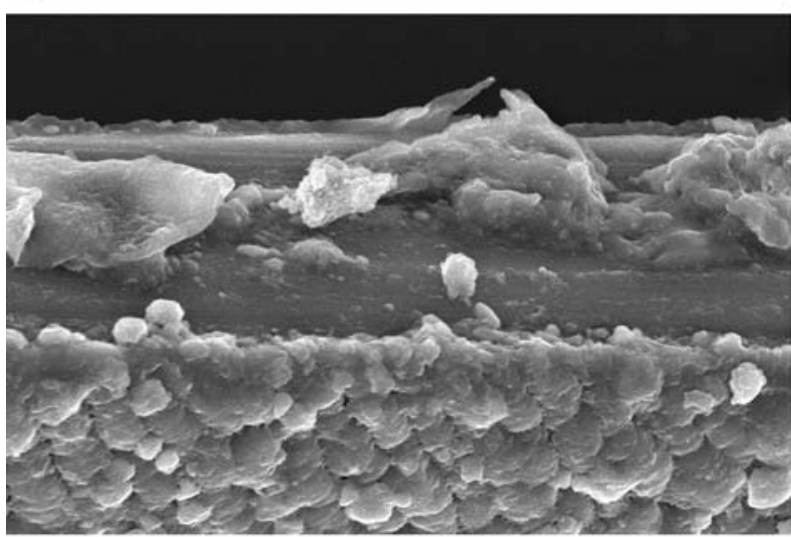

b)

Figure 12. SEM micrographs of fracture surfaces of PP (a) and surface modified PP (b) DENT samples tested in MD 
both fracture surfaces. Fracture toughness parameters, $J_{c}$, reported in Table 1, show that the resistance to unstable propagation is twice when the crack propagates passing through the machine orientation direction (MD) than when it propagates along with it. The observed fracture behavior

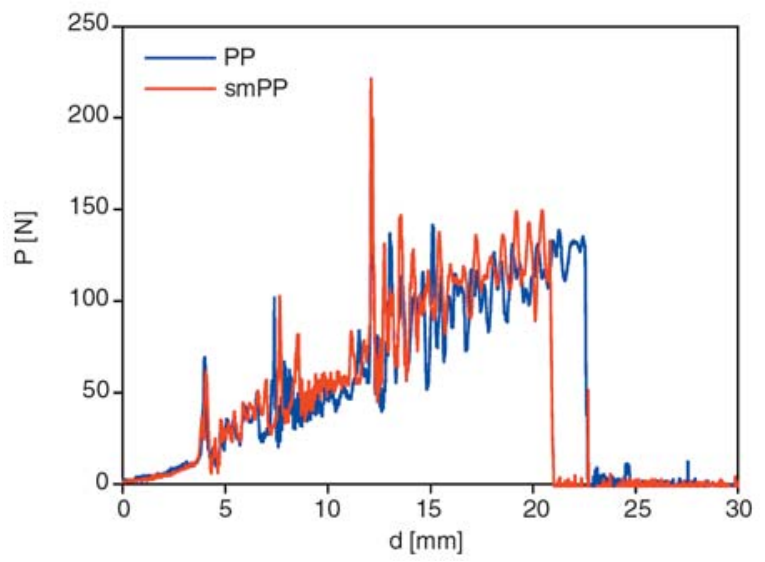

Figure 13. Typical load-displacement curves of PP (a) and surface modified PP (b) samples under biaxial impact deformation

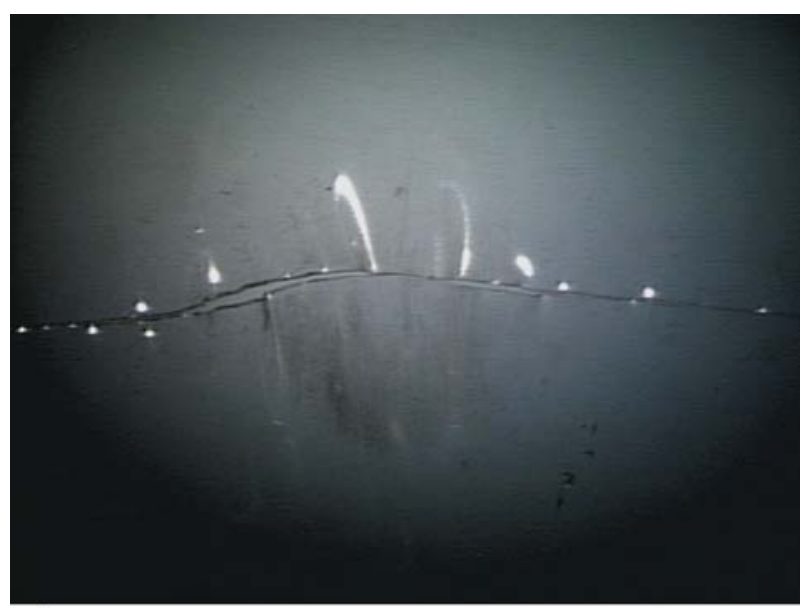

a)

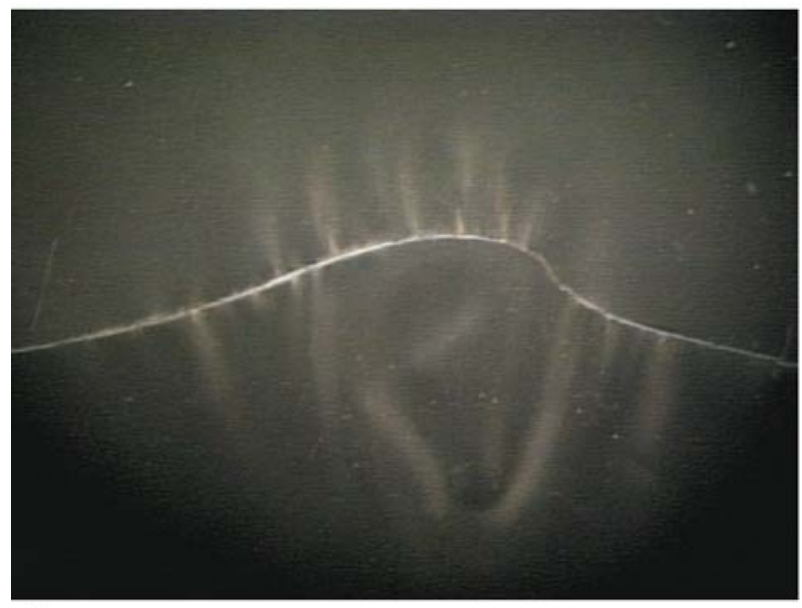

b)

Figure 14. Failure feature of PP (a) and surface modified PP (b) falling dart impacted specimens reflects the imbalanced properties between the machine direction and the comparatively weak transverse direction.

Typical dart impact load-displacement curves are shown in Figure 13 while the derived dart impact properties are reported in Table 1. TOM images of the dart impacted region of PP and smPP specimens are shown in Figure 14. Both films behave in the same way exhibiting a semi-brittle fracture pattern as judged from the load deflection records characteristic (Figure 13) and the feature of the broken samples (Figure 14). Load-displacement curves dropped to zero instantaneously upon reaching the maximum load. A punch-like fractured surface with a punch-out-cap still attached to the specimen and two radial main cracks responsible for the final failure of the specimen are observed in the broken samples.

Both the fracture patterns and the derived parameters point out that the surface modification has not influenced the biaxial impact response of the neat PP film.

\section{Conclusions}

Through this paper a complete investigation of the mechanical response of surface modified polypropylene films by photo-grafting with acrylic acid was carried out. The principal findings are:

- the degree of grafting induced in the films was high enough to alter the topographical pattern and physico-chemical properties of the surface, such as roughness, wettability, hidrophilicity and transparency of PP films. Besides, the presence of specific functional groups offers the opportunity to use them as anchorage sites for further derivatization. They could be used to bond covalently specific organic molecules (dye, antimicrobial or antifungal drugs, etc.)

- the near surface indentation behaviour displayed by the grafted surface indicate that a glassy layer of PAA, which can be viewed as a sort of laminate was formed onto the PP surface.

- uniaxial deformation properties, fracture behavior and biaxial impact performance of the neat films were retained after chemical modification. It is evident that the mechanical response of surface modified film is governed only by PP resistance to deformation, thus, confirming the hypothesis that the PAA chains which were 
strongly attached to the PP film, only interact among each other through the formation of physical entanglements and secondary bonds without constraining the PP surface.

- the beneficial original degree of molecular orientation of neat films was not altered after photografting. This means that the UV-irradiation involved in the grafting procedure induces negligible cross-linking and degradation in the neat PP.

\section{Acknowledgements}

This work was financial supported by CONICET project number PIP 6253 and by ANPyCT Project number PICT $2004 \mathrm{~N}^{\circ} 25530$.

\section{References}

[1] Bhattacharya A., Misra B.: Grafting: A versatile means to modify polymers. Techniques, factors and applications. Progress in Polymer Science, 29, 767814 (2004).

[2] Kwon O. H., Nho C. Y., Chen J.: Surface modification of polypropylene film by radiation-induced grafting and its blood compatibility. Journal of Applied Polymer Science, 88, 1726-1736 (2003).

[3] Chen H. J., Shi X. H., Zhu Y. F., Zhang Y., Xu J. R.: Polypropylene surface modification by entrapment of polypropylene-graft-poly(butyl methacrylate). Applied Surface Science, 254, 2521-2527 (2008).

[4] Xing, C-M., Deng J-P., Yang W-T.: Synthesis of antibacterial polypropylene film with surface immobilized polyvinylpyrrolidone-iodine complex. Journal of Applied Polymer Science, 97, 2026-2031 (2005).

[5] Xu Z-K., Dai Q-W., Wu J., Huang X-J., Yang Q.: Covalent attachment of phospholipid analogous polymers to modify a polymeric membrane surface: A novel approach. Langmuir, 20, 1481-1488 (2004).

[6] Yang J. M., Lin H. T., Wu T. H., Chen C. C.: Wettability and antibacterial assessment of chitosan containing radiation-induced graft nonwoven fabric of polypropylene- $g$-acrylic acid. Journal of Applied Polymer Science, 90, 1331-1336 (2003).

[7] Vartiainen J., Rättö M., Tapper U., Paulussen S., Hurme E.: Surface modification of atmospheric plasma activated BOPP by immobilizing chitosan. Polymer Bulletin, 54, 343-352 (2005).

[8] Lai J., Sunderland B., Xue J., Yan S., Zhao W., Folkard M., Michael B. D., Wang Y.: Study on hydrophilicity of polymer surfaces improved by plasma treatment. Applied Surface Science, 252, 3375-3379 (2006).

[9] Ciszewski A., Gancarz I., Kunicki J., Bryjak M.: Plasma-modified polypropylene membranes as separators in high-power alkaline batteries. Surface and Coatings Technology, 201, 3676-3684 (2006).
[10] Zhang P. Y., Ränby B.: Surface modification by continuous graft copolymerization. I. Photoinitiated graft copolymerization onto polyethylene tape film surface. Journal of Applied Polymer Science, 40, 1647-1661 (1990).

[11] Li Y., Desimone J. M., Poon C. D., Samulski E. T.: Photoinduced graft polymerization of styrene onto polypropylene substrates. Journal of Applied Polymer Science, 64, 883-889 (1997).

[12] Decker C., Zahouily K.: Surface modification of polyolefins by photografting of acrylic monomers. Macromolecular Symposia, 129, 99-108 (1998).

[13] Piletsky S. A., Matuschewski H., Schedler U., Wilpert A., Piletskaya E. V., Thiele T. A., Ulbricht M.: Surface functionalization of porous polypropylene membranes with molecularly imprinted polymers by photograft copolymerization in water. Macromolecules, 33, 3092-3098 (2000).

[14] Chun J., Cho S. M., Lee Y. M., Le H. K., Suh T. S., Shinn K. S.: Graft copolymerization of mixtures of acrylic acid and acrylamide onto polypropylene film. Journal of Applied Polymer Science, 72, 251-256 (1999).

[15] Ma H., Davis R. H., Bowman C. N.: A novel sequential photoinduced living graft polymerization. Macromolecules, 33, 331-335 (2000).

[16] Bamford C. H., Al-Lamee K. G.: Studies in polymer surface functionalization and grafting for biomedical and other applications. Polymer, 35, 2844-2852 (1994).

[17] Rieser T., Lunkwitz K., Meier-Haack J., Müller M., Cassel F., Dioszeghy Z., Simon F.: Surface modification of microporous polypropylene membranes by polyelectrolyte multilayers. ACS Symposium Series, 744, 189-204 (2000).

[18] Sciarratta V., Vohrer U., Hegemann D., Müller M., Oehr C.: Plasma functionalization of polypropylene with acrylic acid. Surface and Coatings Technology, 174-175, 805-810 (2003).

[19] Dogué L. J., Förch R., Mermilliod N.: Plasma-induced hydrogel grafting of vinyl monomers on polypropylene. Journal of Adhesion Science and Technology, 9 , 1531-1545 (1995).

[20] Kato K., Uchida E., Kang E-T., Uyama Y., Ikada Y.: Polymer surface with graft chains. Progress in Polymer Science, 28, 209-259 (2003).

[21] Ränby B., Gao Z., Hult A., Zhang P.: Modification of polymer surfaces by photoinduced graft copolymerization. in 'Chemical Reactions on Polymers' (eds.: Benham J. L., Kinstle J. F.) ACS Symposium Series, Washington, vol 364. 168-186 (1988).

[22] Naguib H. F., Aly R. O., Sabaa M. W., Mokhtar S. M.: Gamma radiation induced graft copolymerization of vinylimidazole-acrylic acid onto polypropylene films. Polymer Testing, 22, 825-830 (2003).

[23] Costamagna V., Wunderlin D., Larranaga M., Mondragón I., Strumia M.: Chemical modification of polyolefin films with acrylic acid as grafting agent. Journal of Applied Polymer Science, 102, 2254-2263 (2006). 
[24] Costamagna V., Strumia M., López-González M., Riande E.: Gas transport in surface grafted polypropylene films with poly(acrylic acid) chains. Journal of Polymer Science Part B: Polymer Physics, 45, 24212431 (2007).

[25] Jagur-Grodzinski J.: Heterogeneous modification of polymers: Matrix and surface reactions. John Wiley and Sons, Chichester (1997).

[26] Aliev R., Gracía P., Burillo G.: Graft polymerization of acrylic acid onto polycarbonate by the preirradiation method. Radiation Physics and Chemistry, 58, 299-304 (2000).

[27] Taher N. H., Dessouki A. M., Khalil F. H.: Radiation grafting of acrylic acid onto polypropylene films. Radiation Physics and Chemistry, 36, 785-790 (1990).

[28] Taher N., Hegazy E-S. A., Dessouki A. M., ElArnaouty M. B.: Graft copolymers obtained by radiation grafting of methacrylic acid onto polypropylene films. Radiation Physics and Chemistry, 33, 129-134 (1989).

[29] Singh A., Silverman J.: Radiation processing of polymers. Hanser, Munich (1992).

[30] Woods R. J., Pikaev A. K.: Applied radiation chemistry: Radiation processing. Wiley, New York (1994).

[31] Briscoe B. J., Fiori L., Pelillo E.: Nano-indentation of polymeric surfaces. Journal of Physics. D: Applied Physics, 31, 2395-2405 (1998).

[32] Fischer-Cripps A. C.: A review of analysis methods for sub-micron indentation testing. Vacumm, 58, 569585 (2000).

[33] Klapperich C., Pomvopoulos K., Pruitt L. A.: Nanomechanical properties of polymers determined from nanoindentation experiments. Journal of Tribology, 123, 624-632 (2001).

[34] Bull S. J.: Nanoindentation of coatings. Journal of physics D: Applied Physics, 38, 393-413 (2005).

[35] Ebenstein D. M., Pruitt L. A.: Nanoindentation of biological materials. Nanotoday, 1, 26-33 (2006).

[36] Frontini P. M.: Nanoindentation: An emerging technique for polymer surface mechanical characterization. Express Polymer Letters, 1, 640 (2007).

[37] Guthrie J. T., Huglin M. B., Phillips G. O.: Graft copolymerization to cellulose by mutual irradiation. Journal of Polymer Science, Part C, 37, 205-219 (1972).

[38] Kaith B. S., Kalia S.: Graft copolymerization of MMA onto flax under different reaction conditions: A comparative study. Express Polymer Letters, 2, 93-100 (2008).

[39] Battle R., Nerín C.: Application of single-drop microextraction to the determination of dialkyl phthalate esters in food simulants. Journal of Chromatography A, 1045, 29-35 (2004).

[40] Read J. C., Duncan B. E., Meyer D. E.: Birefringence techniques for the assessment of orientation. Polymer Testing, 4, 143-164 (1984).
[41] Bartczak Z., Martuscelli E.: Orientation and properties of sequentially drawn films of an isotactic polypropylene/hydrogenated oligocyclopentadiene blend. Polymer, 38, 4139-4149 (1997).

[42] Oliver W. C., Pharr G. M.: An improved technique for determining hardness and elastic modulus using load and displacement sensing indentation experiments. Journal of Materials Research, 7, 1564-1583 (1992).

[43] G'Sell C., Hiver J. M., Dahoun A., Souahi A.: Videocontrolled tensile testing of polymers and metals beyond the necking point. Journal of Materials Science, 27, 5031-5039 (1992).

[44] Ward I. M., Hadley D. W.: Yielding and instability in polymers. in 'An introduction to the Mechanical Properties of Solid Polymers' (eds.: Ward I. M., Sweeney J.) John Wiley and Sons, Chichester, 241-272 (1993).

[45] Grellmann W., Reincke K.: Quality improvement of elastomers - Application of instrumented notched tensile-impact testing for assessment of toughness. Materialprüfung Jahrgang, 46, 168-175 (2004).

[46] Bucknall C. B.: Characterizing toughness using empirical tests. in 'Polymer Blends' (eds.: Paul D. R, Bucknall C. B.) John Wiley and Sons, New York, vol 2. 59 (2001).

[47] Jones D. P., Leach D. C., Moore D. R.: The application of instrumented falling weight impact techniques to the study of toughness in thermoplastics. Plastics and Rubber Processing and Applications, 6, 67-75 (1986).

[48] Sun D. C., Magill J. H.: Thermal interactions in oriented polymeric materials: Shrinkage, crystallization, and melting. Polymer Engineering and Science, 29, 1503-1510 (1989).

[49] Brun C., Delobelle P., Fromm M., Berger F., Chambaudet A., Jaffiol F.: Mechanical properties determined by nanoindentation tests of polypropylene modified by $\mathrm{He}+$ particle implantation. Materials Science and Engineering: A, 315, 63-69 (2001).

[50] Lee S-H., Wang S., Pharr G. M., Xu H.: Evaluation of interphase properties in a cellulose fiber-reinforced polypropylene composite by nanoindentation and finite element analysis. Composites Part A: Applied Science and Manufacturing, 38, 1517-1524 (2007).

[51] Tranchida D., Piccarolo S.: Relating morphology to nanoscale mechanical properties: From crystalline to mesomorphic iPP. Polymer, 46, 4032-4040 (2005).

[52] Joslin D. L., Oliver W. C.: A new method for analyzing data from continuous depth-sensing microindentation tests. Journal of Materials Research, 5, 123-126 (1990).

[53] Huck W. T. S.: Effects of nanoconfinement on the morphology and reactivity of organic materials. Chemical Communications, 4143-4148 (2005).

[54] Ward I. M., Hadley D. W.: An introduction to the mechanical properties of solid polymers. John Wiley and Sons, Chichester (1993). 